Roberto Veraldi

\title{
SOCIETY, COMMUNICATION AND DEVELOPMENT: FOR A NEW SEMANTIC RESOLUTION
}

\begin{abstract}
Summary
Communication for development is a particularly current subject, not only for the interest given by organizations such as UNESCO and FAO, but also the need to respond to the criteria of local development, i.e., a great deal nearer to the citizen and his territory. In other words, while it is true that communication alone cannot bring about development, it is also true that inadequate communication can slow down and make development fruitless, besides encumbering people's participation and it is the key for the development of interaction with the territory. In this paper, I try to combine communication and development, because the new paradigm (the social individualism) as the creator of the society. Social Individualism as a moment of crossing between Holism and Individualism; in such a case, intended as a moment of adjustment between State and Market and as a conjunction of State-Economy-Market for the creation of new social models that will turn into places of daily practices, but which must be transmitted in order to become shared and accepted.
\end{abstract}

Key words: Society, Culture and Communication; local development, social individualism, participation.

The Society is communication: "In that Ego performs a linguistic action and Alter takes position towards it, both enter into an interpersonal relationship" (Habermas, 1985).

The communicative action is conceived in the Habermasiana theory as the highest and most conscious expression of humanity. H. Attacks the ideologies of modernity and postmodernity starting from the paradoxes that see the individual universe subordinate to the imperatives of formal 
systems and, in the philosophical path, tries to affirm a "methodology of sociology", which, in my view, steps for culture.

Through the social system and one of its pillars, culture, we are talking more and more as an engine for the economic and social development of every territory. It is mentioned in the regional policy offices and in the same community documents; In fact, local development and the revival of local communities, such as social systems that have a strong identity, is seen as something that must be strongly communicated and managed culturally.

Communication for development is a particularly current subject, not only for the interest given by organizations such as UNESCO and FAO, but also the need to respond to the criteria of local development, i.e., a great deal nearer to the citizen and his territory. In other words, while it is true that communication alone cannot bring about development, it is also true that inadequate communication can slow down and make development fruitless, besides encumbering people's participation (AA.VV. 1982 : 39).

All the research on the functioning of communication in the politics of development, merged later in the MacBride Report in 1980, is concentrated on what was defined as communication for development: an expression that, even though it does not refer to western regions with sluggish economies but to the plight of third world countries, is able to cover the set of problems relative to social processes based on dialogue, whose aim is the research for change characterized by the development of interaction with the territory.

Let's start from the assumption that the term development is a polysemous term. In a concise way, we can give the generally accepted definition:

The process of change in economic structures; the strengthening of productive capacity, which allows for a superior amount of goods and services compared to the past, changing the socio-economic structures, the cultural models and the expectations.

Giving adequate consideration, for now, to this definition, the question we should ask ourselves is: can we still talk about local development, localism, subjectivity of a specific area in the era of globalization of markets and the planetary control of politics of development?

Development is a fundamental concept in the field of social sciences, around which the theoretical debate is organized. Such a debate, 
however, has left many questions unresolved; among which not having come to a shared resolution. We could add the formula

\section{DEVELOPMENT = MATERIAL GROWTH + WESTERN RATIONALIZATION}

(Caselli 2001 : 12).

This idea of development arises from some visions, up to a short time ago, intensely dominating, and from some resulting conceptions:

a) A strong evolutionist belief that considers development as a linear, cumulative, irreversible process;

b) A strong industrialist belief with a vocation to follow the western model of socio-economic development;

c) A strong ethnocentric belief, closely related to the second model, according to which western reasoning is transformed into a concept of universal validity, and universal values typicamente western, such as entrepreneurial spirit, profit, material security, personal interest are considered in the same way.

The concept of development arises historically as a concept typicamente deeply western, due to the fact that it originated in Europe and spread around the world so much so that in the language of numerous extraeuropean cultures, it is not easy to find terms that bring out the full meaning of development as we interpret it; besides, it cannot be denied that the word development is inclined to indicate the universalization of the benefits of the First World (Latouche 2005. Bianco 2007; Caselli 2001).

Perhaps this is where the problem is: if, on one hand, development corresponds to modernity, identified with its values, western procedures and processes, on the other hand underdevelopment, (the 'fortunate event' model coined by the President of the United States of America, Harry Truman, with the launching of 'Point IV' in the programme of technical and financial help for underdeveloped countries, later analized by the expert Walt Whitman Rostow in his famous 'Theory of Stages) corresponds to tradition, connected to effectiveness, procedures and processes different from western ones. 
It is in this perspective that tradition and local habits are interpreted as the main obstacle in development. As a matter of fact, as a logical consequence, if it is thought that the western techno-cultural model is universal, anything other than that becomes a model to avoid.

This perspective, however, comes as a failure if we think of the concrete case of Asian economy, which makes of its tradition and local culture its main strength of growth.

Take the case of the Asiatic Tigers that have made tradition their main strength: or the case of those numerous 'local' enterprises that have made of their dialectical relationship with the social and economic materials of the past, a re-discovery for the new social economy (for instance Decentralised Hotel (Dall'Ara 2009) which arises as a horizontal hotel characterized through a series of requisites which developed after a long series of experience in the sector and launched in the eighties in Friuli and Sardegna and is present at Santo Stefano of Sessanio in the Abruzzo, which represents a new model of holiday offer based on the reclamation of existing property and valorized with local resources, as well as being immersed in modernity and interconnections with the world).

This fact leads us to think that development should not be considered only as an economic perspective, thereby reversing the meaning of tout-court growth, which only economists could and should specialize in.

And going back to the beginning, development is a polysemous term, but in its concept it has the deep idea of development as the emancipation of mankind. As Marco Caselli reports: development of the people, for the people and by the people. Ultimately, development as a process of the expanding choice of the people, a possibility to lead a long and healthy life, gain knowledge and access the necessary resources in order to have a good standard of living; thus, the formation of human capacity and the use of acquired capacity. Whereby income becomes only one of the options that people would like to have but it does not represent the total sum of the life of mankind. Development, therefore, must be something more than the mere expansion of income and wealth. Its main aim should be the individual (UNPD 1993a).

Therefore, if the action of social actors is at the centre of development and if the social actors are to be referred to societies in which they 
carry out their relational activities (the construction of the social field by Pierre Bourdieu (2004) or that social arena, which I intended as a new semantic construction, on the strength of which every social actor constructs rationally his reality through his social relationship with other individuals, adapting it or modifying it constantly, transforming the_mechanism of the theory of structure of Antony Giddens (Ghisleni and Privitera 2009 : 116), with the variation, proposed by me, that in the carrying out of social procedures, the structural features are not 'temporarily present only at the moment of the constitution of social systems', because if that were the case, they would become an intentional action; on the contrary, just because they comply with the human/relational sphere, they are inborn in the sociality of the individual: he transforms his actions into actions of social individualism in such a way that they affect the realization of the whole social reality, becoming a rational and empiric consequence of his natural inclination towards the social engineering of reality, which becomes visible but only at the moment of the flexible construction of new objectivity, but which is always present in everyday activities, apart from the putting into practice or not of the generative behaviour of new 'social facts'), fulfilling in fact new social consequences and adapting them in continuation to the changes in use; following this, the problem will become that of a new definition of development: we could perhaps talk about coalition development as a moment of connection and of synthesis between relational capacity, economic capacity and cultural capacity, intended as the appreciation of tradition; however, where development does not fall into the category of developmentalism, an expression very dear to Latouche who claims that the idea of development is by now a toxic action and a lethal choice for the new generations if it does not lead to a rethinking of the concept itself (Latouche $2009: 18$ ), besides indicating as well that 'it is the idea itself of development that is disappearing from the scenario as a direct consequence of the modern western genius, also in decline, according to which scientific and technological progress would necessarily get better and consequently living conditions of all the people on the earth (Besancon 1992).' It is not a local development like oxymoron that comes into contrast with the peculiarity of growth as a consumption and the locale as attention towards tradition and sustain- 
ability, but a development (coalitional, exactly) that produces circular movements of awareness, people, economies different from one another and of mixed origins giving each of them the same degree of dignity and arriving at a new construction of social reality, with repercussions both flexible and tangible, as all of them have their own dignity and a socialhistorical perspective in a global panorama.

This implies a Governing-Action of globalization and an effective communication of the phenomena in use for the realization of the right territorial consideration of the social arena referred to, to avoid interconnection among local networks being transformed into a concatenation among dominant social realities towards dominant societies; resulting in a kind of decrease of national supremacy of the most fragile realities, forgetting that all societies have, due to their own nature, the same equality and dignity inside the new social arena.

In the course of the last few years, as a matter of fact, the phenomenon of globalization has been brought to the world's attention. Globalization, in the presence of profound changes that cannot find explanations in traditional ideologies, has ended up acquiring a paradigmatic meaning which should explain any fact or event that comes about in politics and in economy. Ultimately, there should be set up the existence of a space (and an efficient connected tool), in which local systems can claim their own identity and their own capacity for growth.

Naturally, if there should be an acceptance in a way which is too passive, those interpretations of globalization which see the phenomenon as a threat for local identities, the hopes for an autonomous growth of local social realities, would be certainly destined to create a lot of doubts; in fact, if we heed these fears, the socio-economic system set up at a mondial level would, with the empirical evidence demonstrated, make the awareness of local territory impossible as well as the putting into operation of systems of new socio-economic relationships among the same territorial areas, even though they are inserted in global environments (always intended as interconnection of local networks of situational factors) [Veraldi 2007a, b].

For this reason we need to understand if this fact remains a unique scenario or the finale of an open-ended film with various solutions. 
From this point of view, the most borderline feature is that of an attempt, desired by the World-System as a rationalization of the economic reality, to relieve the local realities of responibility through programmed approaches of mandate towards 'other' kinds of decision-making that do not represent and are not the expression of local reality and above all are not aware of the particularities and vocations of the 'locale'. Whereas, the cognizant act of self-protection and self-recovery in the micro world towards the macro world, brings about a stance of prestige of the locale towards the global, which has got in its most fortunate expression (Globalization), its strongest connection -a relationship that calls into balance the System of social relations. For which reason, global not towards locale, but a response connected to the ongoing changes for the appreciation of those social arenas that measure the society in total.

Conversely, however, we need to take into account Serge Latouche's lesson, when he claims that globalization of the economy [with its negative implications, N.d.A],comes about in full only with the transformation of all the perspectives of life regarding economic issues, let alone the goods. [...] ; globalization is in fact also technological and cultural, and covers the totality of the planet (Latouche $2010: 17,2007$ ).

Thus, the problem will be to set up strategies of self-government of meaningful self-built projects of local autonomy, which should give rise to activities for promotion of local development (what I intend is Coalition Development, in which Social Individualism finds application and synthesis; social Individualism as a moment of crossing between Holism and Individualism; in such a case, intended as a moment of adjustment between State and Market and as a conjunction of State-Economy-Market for the creation of new social models that will turn into places of daily practices, but which must be transmitted in order to become shared and accepted.

As a matter of fact, citizens socialize and declare themselves active part of a community through the memory of places and through the history of places. 'A society', according to the definition of E. Durkheim, ' is not simply made up of the mass of individuals in it, of the territory that they occupy, of the things they use, but it is made up first of all of the idea that it forms of itself (Durkheim 1982)'.

Places are not unchangeable objects, they are abstractions, they break up, they come together again in different forms, the boundaries are 
mobile; in other words they age, they transform, they die, they revive. Together with the places, also their history ages. The history of a territory is old when the experience is trivialized, when the ways of getting out are broken, when there is no possibility of imagining a future.

This is what seems to be going on in many places today in our country, bound in scolastic history and in local boundaries marked before the arrival of the mobility mass, when the majority of Italians went to work, did their shopping, accompanied their children to school on foot, by bicycle, on mule back or by trains much slower than today. It has to become the history of living territories: narrated to become acquainted with and narrated in order to compete (Tantillo 2008).

Therefore, what has got to be reconsidered is that concrete connection which, in the totality of a socio-historical fact, constitutes that particular element of cohesion between an ideological fact and the social result (in other words which explains, sociologically, the internal cultural dynamics [Malizia, 1999 : 14], i.e. an assimilated culture, lived and communicated so as to make it a unifying feature and ideologically established on new social realities), so that it will become a foundation for the relationship between its present and its past, as a resource of a vision of society which is projected towards the future, towards the control and planning on a rational basis of change (progress) [Vardanega 2009].

If social and economic research deals with living territories (as Tantillo has confirmed) it must, in my opinion, necessarily put Social Individualism and Coalition Development at the centre of its reflections and its history. It needs to change its perspective: give importance as well to the patrimony of immaterial culture and the patrimony connected to activities, because these activities (as i meant above) are producers of economy or generators of society, through their results both in a material and an immaterial sense.

With a crumbling society, in conditions of precariousness and the victim of a serious territorial weakening, affecting both the dwindling services for people and enterprises and the pulverization of commercial stuctures and low levels of productivity, new paths of reflection and social engineering, influenced by a sort of mass return culture that would give respite to the centrality of the territory and the factors in it, are needed. 
At the basis of this inversion of trend there would be both the desire to devise a different quality of living and the will to retrieve those places at times perceived as the original ones (Tantillo 2008).

Therefore, we must reinvent history, reinvent the formulas of history, reinvent the procedures for an efficient activity of communication in the local and communal territories, the inner part of the scenario freshly marked with a coalitional development (already explained as a synthesis among relational capacity, economic capacity and the cultural capacities intended as the appreciation of tradition). In extreme synthesis, another way of considering development; or an alternative idea to development as it is set up now and which, therefore, denotes an inconsistency with the semantic definitions of the past and with the contorted explanations of the present economies; thus, through a strong recall to the creativity of local communities (where, in a Pareto sense, the instincts of combinations are strong) we have to reach the creation of a new socio-economic strategy through the operation of a deconstruction of an imaginary economy that necessarily passes to a new form of communication of the economy itself in the role of universal economy; the latter, in my opinion, represents the contrary of a cultural and historical construction: this means that is possible to change it.

Such a change must, however, pass through the division of supremacy of only one governing body (in this sense, what Pierre Bourdieu affirmed when talking about the field of economy and sociology, declaring that both of them analyse the products of a social construction, in such a way that it is not possible to describe adequately the economic processes without referring to sociology. Instead of opposing them, as happens traditionally, this is the moment to understand that sociology and economy actually constitute one identical governing body which has as its goal the analysis of social facts, of which economic transactions represent above all only one perspective) [Bourdieu 2004], and open up to the sharing between the governing bodies through the call towards a consideration on the matters that have, for a long time, been interfering with our socioeconomic models and are on the point of devising new ones; the attempt is to create a value 'the break-up generated by the decline of the economy', which arises with the depletion of the significant imaginary founders of the economic periods. 
Pulling out of the economy [this type of economy which is not founded on economic ethics (Cfr. R. Veraldi 2009) and is not founded on the Person/individual as the proprietor of the currency (Auriti 2002) in terms of owner of subjective rights and, among these, a new formulation of the income of citizenship, $\mathrm{Nd}$.A] clearly means pulling out of capitalism and breaking off with the westernization of the world (Latouche 2005) also through compromise and hybridization.

However, this takes on another meaning: take into one's own hands the destiny of one's own territory, giving new life to the marginalized, giving hope to the excluded, redesigning the cultural and spatial boundaries through putting into practice and sharing new social contexts in the way of communicating, whose protagonists, even with limited means of a complex society, show that they are able to become spokespeople for a critical revision of their own traditional connections (Malizia 2009).

\section{Bibliography}

AA.VV Communication and society today and tomorrow. MacBride's report on the problems of communication in the world. RAI-ERI Edizioni, Rome, 1982.

Auriti G., The Utopian Country, Solfanelli Editore, Chieti, 2002.

Besancon K., The Collapsing Vision of Global Development (conference of the PNUD), Bucarest, September, 1992.

Bianco A., Introduction to the Sociology of development, FrancoAngeli, Milano, 2007.

Bourdieu P., The social structures of economy, Asterios Editore, Trieste, 2004.

Caselli M., Measuring development. Procedures and problems, ECIG, Genova, 2001.

Dall'Ara G., How to project a plan of territorial touristic development, Halley Editore, Matelica, 2009.

De Simone A., Oltre il disincanto. Etica, diritto e comunicazione tra Simmel, Weber e Habermas, PensaMultimedia, Lecce, 2006

Durkheim E., Elementary forms of religious life, Edizioni di Comunità, Milano, 1982.

Ghisleni M., \& Privitera W., Contemporary Sociology, Bauman, Beck, Bourdieu, Giddens, Touraine, UTET, Novara, 2009.

Latouche S., The invention of economy, Bollati Boringhieri, Torino, 2005.

Latouche S., How to survive development, Bollati Boringhieri, Torino, 2009.

Latouche S., The end of the western dream, Essay on the Americanization of the world, Elèuthera Edizioni, Milano, 2010.

Malizia P., Lessons on the sociology of culture, Aracne, Roma. 1999.

Malizia P., Communications. Structures and social contexts of communication operations, FrancoAngeli, Milano, 2006. 
Tantillo F., Abruzzo Reset: an experimental project for the knowledge and communication of the territory, in Tafter Journal, no. 4, May 2008.

UNDP, Report on human development. How to decrease world inequality, Rosenberg \& Sellier, Torino, 1993a.

Vardanega A., Tradition as an ambivalent resource for local development, in EthicEconomic-Societies. Social and economic systems in transition, by Veraldi R., Edizioni Universitarie Romane, Roma, 2009.

Veraldi R., Globalization and local society. Edizioni Universitarie Romane, Roma, 2007.

Veraldi R., Manuario, Work in progress on sociological matters. Aracne, Roma, 2007.

Veraldi R., Ethic-Economic Society. Social and economic systems in transition, Edizioni Universitarie, Romane, Roma, 2009. 